\title{
An Investigation: Should Organizations Move towards Team-Based Recognition?
}

\author{
Mr Nelesh Dhanpat \\ Department of Industrial Psychology and People Management, Faculty of Management, University of Johannesburg \\ Auckland Park Kingsway Campus, PO Box 524, Auckland Park, 2006, Johannesburg, South Africa \\ Email: Neleshd@uj.ac.za
}

\section{Doi:10.5901/mjss.2014.v5n23p2363}

\section{Abstract}

This paper presents the occasion for organizations to investigate the need to transition towards a team-based approach of employee recognition. A theoretical framework of employee recognition is presented. Employee recognition is largely recognized as a managerial practice, and have been in practice in terms of individual-based recognition within organizations. Many organizations are looking for a way forward to approach this matter in a strategic manner, and understand the implications of team-based recognition on employees and the organization itself. Employee recognition has placed major impact on work performance, team effectiveness and organizational success. The paper explores motivational theories linked to employee recognition and elaborates on the effective utilization of recognition programs. Subsequently, the impact of employee recognition on employees are reviewed. The consequences and implications of team-based employee recognition are further evaluated. The paper is a qualitative study based on utilizing secondary data and presents a conceptual paper. The current study has reviewed various literature on remuneration, compensation, employee recognition, motivation and teamwork. This paper further suggests that organizations needs to be cognizant of the implications and consequences of team-based recognition on employees, work outcomes and employee behaviour.

Keywords: employee recognition, recognition programs, rewards, remuneration, teams and groups

\section{Introduction and Background}

It is widely acknowledged that people work as a form of socio-economic activity. The $21^{\text {st }}$ century organizations have contributed to the multiple adjustments which employees need to make due to the continual changes of the modern work environment and hence, forcing managers and employees to react to unacquainted and contradictory demands placed. This can pose a real challenge to achieve consistency and balance in their job. Consequently, employees will need to place extra effort and perform increasingly complex and burdensome tasks and undertake challenging activities. Subsequently, this will compound an employee's need for recognition (Collerette, Schneider \& Legris 2001; Brun \& Dugas, 2008).

Organizations have utilized various strategies to enhance employee morale and engagement. One such motivational strategy that has garnered much attention over the years and is currently in practice within organizations, to individual employees, is the concept of employee recognition (Fey, Anseel \& Wille, 2013; Brun \& Dugas, 2008; Long \& Shields, 2010). Evidently, organizations have placed much emphasis on the importance of offering awards and incentives that validates and recognizes exemplary and outstanding performance and effort. Therefore, it is imperative to note that employee recognition has become much of an organizational and managerial issue, as it is closely related to the basic needs of employees within an organization (Brun \& Dugas, 2008).

Although organizations often fail to differentiate between rewards and recognition, which are regarded as a single phenomenon, by awarding employee's large bonuses and merit pay. Evidently, this results in unhappy and demotivated employees and hence, creating a committed and engaged organization becomes difficult to establish (Hasnsen, Smith \& Hansen, 2002). It is imperative to note that reward and recognition depicts two different mechanisms. According to Bussin (2012), rewarding employees based on incentives are characterised as forward looking namely, compensating employees based on a predetermined set of criteria communicated prior to the performance cycle. In comparison, recognition is characterised as backward looking, since employee behaviours are rewarded after they have been achieved (Bussin, 2012; Long \& Shields, 2010; McAdams, 1999).

Bussin (2012) noted that employee recognition plays an increasingly pivotal role in the structure of an organization's total compensation and reward system. Therefore, an organization's total reward system should include recognition plans and programs. Evidently, recognition plans in the total reward system are aimed at organizational 
behaviours and cultural values. This paper defines employee recognition based on the examination of scientific literature and other closely related topics. Therefore, this paper aims to investigate, conceptually, if there is a need for organizations to move towards team-based recognition.

\section{Problem Statement}

It has been reiterated on numerous occasions that people are an organizations greatest asset. However, due to complexities, greater pressure is being placed on organizations; thus, impacting employee's work and performance. Work is becoming ever so complex and work tasks have significantly intertwined and presents the need for cooperation from team members. This has led to employees and the work itself becoming interdependent. This has presented a new set of challenges in the measurement of individual output and hence, the need to investigate the need of moving towards teambased recognition.

\section{Motivation of Study}

There is an urgent need for organizations and human resource professionals to seek techniques and answers to the concern of how best to recognize the successes and accomplishments of employees. Furthermore, it is essential that managers are able to address the need to recognize employees and hence, the need to link recognition to human capital and understand the value placed on employees. To date literature on employee recognition has been vague. There is room for the theory of employee recognition to be conceptualized and an urgent need to address the challenges put forward.

\section{Research Questions}

The following research questions will be considered:

1. What is team-based employee recognition?

2. What are there implications of team-based recognition on employees and the organization?

\section{The Aim and Objectives of the Paper}

1. To evaluate team-based employee recognition.

2. To evaluate the implications of team-based recognition on employees and the organization.

\section{Design/Methodology}

The paper is a qualitative study based on utilizing secondary data and presenting a conceptual paper. The study reviewed various literature on remuneration, compensation, employee recognition, motivation and teamwork.

\section{Theoretical Framework}

\subsection{Defining Recognition}

It is evident that human resource specialists and practitioners are repeatedly seeking answers and methods to best reward and recognize employee's performance, innovations and achievements (Allen, Houston \& Mann, 2008). According to Brun and Dugas (2008), recognition is considered as an interactional perspective that involves the concept of mutuality. Thus, employee recognition takes into account the bidirectional nature of all human relationships. Taking this into cognizance, such a perspective establishes that the expression of recognition presumes the formation of a bipolar relationship between two or more employees and therefore, can be expressed by either party.

World at work (2008) noted that employee recognition involves acknowledging or giving special attention to employee actions, efforts, performance and behaviour. Bussin (2012) concurs that recognition provides a window of opportunity to reward employees for their contributions and places much emphasis on the psychological value provided to the employee versus the financial value provided. Thus, it is essential to note that all employees have a need for praise and recognition, and essentially line managers and supervisors are in the best position and capacity to provide some sort of recognition. However, there are a few managers and supervisors that do it often enough. Employee recognition 
includes formal and informal programs giving special attention to employee efforts and performance.

According to the work psychodynamics theory, recognition includes two fundamental components namely, the sense of acknowledgement and the sense of gratitude (Dejours 1993). The reference of this type of recognition is to actual work and not the work prescribed to employees by the organization. This type of decision tends to be commonly resisted by management because it points to deficiencies. Recognition exists in the sense of gratitude and highlights an employee's contribution to the performance of work. However, it has been noted that this form of recognition is even less forthcoming within organizations.

In addition, recognition is derived from an acknowledgement or judgment of work that has been accomplished and is expressed in two ways namely, benefit judgment and beauty judgment. Benefit judgment is largely issued by employees in a supervisory capacity, and addresses the social, economic and technical benefits of an employee's work. Beauty judgment is evident by employees who are in a better position than other employees to judge the quality of work performed, including efforts placed. In passing judgment, the group recognizes that employees performed their work according to accepted standards and practices.

\subsubsection{Motivational Theories of Recognition}

Employee recognition serves as a powerful tool in rewarding employees and is definitely not a new concept. There is a large volume of published studies which have investigated the impact of motivation on work on performance (Herzberg, Mausner \& Snyderman 1959; McGregor 1960; Vroom 1964; Porter \& Lawler 1968). These studies have underlined that employee recognition as an essential component of motivation. Herzberg's (1966) hygiene-motivator distinction draws onto the reward-recognition distinction. Furthermore, Herzberg (1966) distinguished that regular and consistent application of formal and informal recognition programs can provide an organization with the impetus to influence employees based on the organization's values and missions.

Moreover, Kim (2006) noted that employee recognition programs elicit specific types of behaviour from employees. Evidently, appropriate behaviours can be maintained and repeated. Likewise, Robbins (2005) associated employee recognition programs to the reinforcement theory, and held that immediately rewarding behaviour, following that behaviour, with recognition is likely to stimulate its recurrence. It is imperative to note that the objectives of research on motivation are no longer restricted exclusively to the attainment of work performance and have progressed to respond to new management issues, challenges and concerns which are related to employee recognition (Browne 2000; Franco, Bennett, Kanfer \& Stubblebine, 2004; Saunderson, 2004). Evidently, several authors have highlighted employee recognition as a route of motivation (Dutton 1998; Appelbaum \& Kamal 2000; Cave, 2002; Saunderson, 2004; Grawitch Gottschalk \& David, 2006). Lawler (1992) noted that group and organization wide rewards are effective. However, it is imperative that employee recognize the link between their actions, performance, and those rewards to be operational.

\subsubsection{Recognition Programs}

An employee recognition program focuses on encouraging employees' specific types of behaviour and ensures that appropriate behaviours are repeated and maintained (Allen et al., 2008; Kim, 2006). Stolovitch, Clark \& Condly (2002) noted that the role of employee recognition programs are closely linked to the quantity and quality of the employee performance. This will produce the greatest impact on the overall business value.

According to Gerhart, Rynes and Fulmer (2009), there have been a great deal of discussions on motivating employees via monetary incentives. Hence, there is a need for alternative means to motivate employee behaviour through the introduction of non-monetary or non-cash employee recognition (Bruns \& Dugas, 2008, Fey, Anseel \& Wille, 2013). Furthermore, organizations and mangers can invest by recognizing and acknowledging employees by asserting a simple thank you or a simple thank you note, certificates of recognition and appreciation, or just commending employees on a job that is well done (Kim, 2006). Empirical studies affirmed the utilization and adoption of employee recognition. Evidently, this leads to positive results in organizations (Stajkovic \& Luthans, 2001, 2003).

Bussin (2012) indicated that cultural implications need to be integrated when designing recognition plans namely, team rewards, peer-to-peer-nominations and organizational values. In light of this paper, team-based recognition and rewards will be outlined. Although individual achievement is promoted through the utilization of recognition plans it is imperative that organizations take cognizance of team rewards. Team rewards, as part of the total rewards, need to be incorporated in recognition plans and hence, incorporated in team structures. In addition, organisational values need to be considered, as well as the organization's culture. According to Huff (2006), recognition programs are established for good reasons namely, improving the culture of recognition. However, in many organizations employee recognition 
programs are not fully integrated in the various aspects of the business strategy and desired culture. Consequently, this can result in a failure to capture the full value of employee recognition programs.

Recognition programs need to be carefully crafted rationally and formulated based on sound theory and integrated with the organization's strategy in mind. An employee recognition program which recognizes behaviours will most likely affect the organization's value and utilises tangible or non-tangible rewards that employees value, so that they will produce value in return (Daniel \& Metcalf, 2005; Huff 2006). It is essential the reward and recognition programs are aligned with the organizational goals, directions and values. In addition, to ensure such programs fit with the direction, goals, values and culture of the organization, and meet the needs of employees then it needs to be revised frequently.

\subsubsection{Impact of recognition on employees}

There is a collective emphasis on team-based work within organizations, and research suggests that a growing reception and awareness on team-based rewards is needed. Therefore, organizations are embracing the conventional way of thought that team-based pay is the best way to encourage cooperation (Merriman, 2008). A lack of recognition can run the risk of psychological distress in the organization (Brun \& Biron et al. , 2003). For managers, this would result in a stress tolerance factor, and also a vital component in aiding their ability to handle difficult professional situations (Dany \& Livian, 2002). Evidently, employee recognition plays a significant role in the accomplishment and stability of organizational change (Atkinson 1994; Fabi, Martin \& Valois 1999; Evans 2001). It is imperative to note, admittedly, employees do express a need to be recognized by their supervisors, colleagues, and clients regardless of their job, level, tenure and status. Employee recognition can include acknowledgement of employees in the form of praise or some form of awards, which can be team or individual-based. Evidently, a lack of recognition cited by Brun and Biron et al., (2003) reveals that an absence or a lack of recognition constitutes the second-largest risk factor for psychological distress in organizations. According to Chillemi (2008) group-based rewards and recognition are ideal when employees care about the wellbeing of others. Likewise, Drake, Wong, and Salter (2007) have identified that feedback, rewards and recognition affect feelings of empowerment among employees.

Cave (2002) and Allen et al., (2008) affirms the need of a combination of team and group based rewards and individual-based rewards. However, Cave (2002) asserts that an emerging line of thought prevails with regards to the danger of incentives on organizations. The need for employee recognition is a prerequisite; however, financial incentives may reinforce organizationally destructive behaviour. Therefore, there is a bigger need for employee recognition of nonmonetary value. According to Allen et al., (2008) employee rewards that recognize purely individual performance as an alternative of group performance and therefore, can drive employees to behave out of self-interest and to challenge the efforts of other employees/co-workers. Conversely, rewards that are based only on group or team performance could allow employees to non-perform, to slack off, and to benefit from other employees' efforts within the group. According to Verespei (1999), recognition and reward programs should encompass an element of individualisation which can be based on the age, life stage, general preferences and occupations of employees.

\subsection{Consequences and Implications of team-based employee recognition}

Organizations may take several approaches in structuring team-based rewards including gainsharing, profit sharing, incentive pay and recognition, all of which can be an effective way to reward team performance.

However, any form of rewards needs to be well structured in order to avoid any unintended consequences that may undermine employees' initiatives and the organization's goals. According to Bolch (2007), the advantages and disadvantages to employee recognition are, respectively, recognition programs are easy to implement which are distributed at a team level and can be easily introduced. However, such programs may raise concerns for employees, as they may be anxious that that they would not be recognized for their own contributions and hence, carry less front-end motivation.

Thompson (2008) indicated that team-based rewards are most effective in high trust situations. Conversely, teambased rewards can unsettle team trust dynamics. Bolch (2007) indicated that gauging peer feedback to single out and reward individual team members with extra recognition can disrupt team dynamics thereof.

In addition, perceived inequality regarding the contributions of employees with in working teams can also reduce cooperation and create motivational loss with in a team-based rewards environment. Consequently, team-based rewards may fail to acknowledge individual differences of employees and may encourage free riding and social loafing (Thompson, 2008); whereby, some employees may restrain from working and still receive the rewards by letting others do the work and hence, team-based rewards may be difficult for some employees to accept (Haines \& Taggar, 2006). 
The incorrect implementation of team-based rewards can have adverse effects and instead of resulting in cooperation it can lead to destructive and competitive behaviour between teams and among team members (Thompson, 2008). In addition, the perception of unfairness may become prominent for high performers as they may evaluate teambased recognition and rewards as unfair (Cable \& Judge, 1994; DeMatteo, Eby \& Saubderstorm, 1998; Shaw, Duffy \& Stark, 2000; Haines \& Taggar, 2006).

\subsection{Realizing the need and benefits of team-based recognition}

The implementation of any team-based incentive program requires the establishment that pay incentives and rewards acts as a communication and motivation device. In addition, people's behaviour is readily influenced by the way they are measured, rewarded and recognized. Therefore, if employees are required to work in groups or teams then there is a need for performance goals to be set as a team, and subsequently reward employees as team members, as they belong to the team.

More importantly, recognition have become an integral part of teamwork. According to Cacioppe (1999) rewards can be given based on individual behaviours displayed by employees' performance. In addition, rewards and recognition can be given to the entire team, and equally divided amongst employees, based on team performance. In doing so, rewarding the entire team or dividing the reward equally between all the employees of the team, based on the team performance is referred to as team-based performance.

It is imperative that organizations take a holistic approach towards team-based recognition by ensuring their goals and strategy are supported by the team culture, including the team competencies and their roles within the reward system and organization. Thus, reward strategies need to be regularly modified and aligned to meet the strategies and goals of the organization in keeping with culture of the competencies needed. Prior to the introduction of team-based rewards, the major aspect of team effectiveness needs to be taken into cognizance (Robbins, Waters-Marsh, Cacioppe \& Millet, 1994).

Employee recognition can be used to develop relationships by encouraging cooperation among employees and assist in working towards common goals of the team and organization. In addition, recognition strategies can also promote learning and development by encouraging risk taking and being involved in new initiatives. According to Coli (1997), to determine whether rewards are appropriate for individuals within teams and for teams as a whole, four factors need to be considered namely, stages of team life cycle, reward and recognition categories, type of teams, public, private or not-for-profit sector and culture of the team and organisation.

Currently, organizations are transforming themselves with a decline in hierarchical levels and have endowed employees and have established processes on teams rather than focusing on individual performance. Evidently, rewards and recognition systems are an essential part of the change that are required for such transformation to be effective. Fundamentally, there is a need for the reorganization of incentive programs to encourage new employee behaviours intended to realising team and organizational goals. Subsequently, the types of teams operating and the stage of teamwork will prescribe the incentives to be utilized in order to accomplish meaningful team and organizational goals (Cacioppe, 1999).

\section{Recommendations and Conclusions}

This paper is an attempt to shed some light on employee recognition from a team-based perspective, providing an opportunity for organizations to consider a transition from individual-based recognition to team-based recognition, in light of the increasing prevalence of teams in the workplace. Evidently, it is duly noted that effective recognition and reward programs can harness and foster a positive environment in organizations; thus, allowing employees to flourish and thrive.

The efforts of employee recognition contributes to organizational success and can and may be the answer to meet the productivity, motivation, and retention challenges faced by today's turbulent organizations. Recognition is a significant part of an employee's job and needs to be clearly linked to performance over which employees can control to be effective. The impetus of motivational theories have examined employee recognition as instrumental source of motivation of work performance.

There may be cases where organizations deem that individually based reward and recognition programs may not support a team-based approach. However, it is essential that organizations develop and maintain employee recognition plans and ensure the alignment of such programs to contribute to the organizational culture. Evidently, it has been identified that team-based rewards and recognition have both potential advantages and disadvantages for an organization. In addition, team-based recognition can be effective in highly interdependent work team environments when reward measurements are fair and clear. However, the outcome of team-based recognition can result in motivational loss, 
competitive behaviour, psychological distress and social loafing. It is clear that organizations need to take cognizance of this when developing a reward and recognition program, and to ensure it is not a one size fits all approach.

In addition, it is essential that reward and recognition programs must also fit in with the culture and values of the organization. In order for organizations to move towards team-based recognition, it is essential that they take into cognizance of the team characteristics and effectiveness, characteristics of the reward system and the organization.

\section{References}

Allen, N., Houston., D. \& Mann, R. (2008). Best practices in New Zealand organizations for rewarding and recognizing employee innovations and achievements. Total Quality Management \& Business Excellence, 19(1/2), 125-139.

Appelbaum, S.H., \& Kamal, R. (2000). An Analysis of the Utilization and Effectiveness of Non-financial Incentives in Small Business. The Journal of Management Development, 19 (9/10), 733-763.

Atkinson, C. (1994). Continuous Improvement: The Ingredients of Change. International Journal of Contemporary Hospitality Management, 6(2), 6-8.

Bolch, M. (2007). Rewarding the Team. HRMagazine, 52(2), 91-93.

Brun, J-P., Biron, C., Martel, J., \& Hivers, H. (2003). Evaluation of mental health: an analysis practices of human resources management. Montreal: Institute for Research Robert-Sauve in health and in security work.

Brun, J., \& Dugas, N. (2008). An analysis of employee recognition: Perspectives on human resources practices. International Journal of Human Resource Management, 19(4), 716-730.

Bussin, M. (2012). The Remuneration textbook of Africa. Randburg: Knowres Publishing (Pty) Ltd.

Cable, D.M., \& Judge, T.A. (1994). Pay Preferences and Job Search Decisions: A Person-Organization Fit Perspective. Personnel Psychology, 47(2), 317-348.

Cacioppe, R. (1999). Using team individual reward and recognition strategies to drive organizational success. Leadership \& Organization Development Journal, 20(6), 322-331.

Cave, M. (2002). Go ahead, motivate me. Australian Financial Review Boss, May, Fairfax Publishing, Australia.

Chillemi, O. (2008). Competitive versus Collective Incentive Pay: Does Workers' Mutual Concern Matter? Economic Theory, 35(1), 175186.

Collerette, P., Schneider, R., \& Legris, P. (2001). Managing organizational change: change in the turbulence, ISO Management Systems.

Daniel, T.A., \& Metcalf, G.S. (2005). The fundamentals of employee recognition. White paper, Society for Human Resource Management.

Dany, F., \& Livian, Y-F. (2002). The New Executive Management: employability, individualization and life. Paris: Vuibert.

Dejours, C. (1993). Labour mental wear; psychopathology has psychodynamics of work. Paris: Bayard.

DeMatteo, J.S., Eby, L.T. \& Sundstrom, E. (1998). Team-based rewards: current empirical evidence and directions for future research. Research in Organizational Behavior, 20, 141-83.

Drake, A. R., Wong, J., \& Salter, S. B. (2007). Empowerment, Motivation, and Performance: Examining the Impact of Feedback and Incentives on Non-management Employees. Behavioral Research in Accounting, 19(1), 71-89.

Dutton, G. (1998). The Re-enchantment of Works. Management Review, 87(2) 51-54.

Evans, R. (2001). The Human Side of School Change; Reform, Resistance, and the Real-life Problems of Innovation. San Francisco: Jossey-Bass.

Fabi, B., Martin, Y., \& Valois, P. (1999). Promoting organizational commitment of people working in organizational transformation: some promising avenues for management. Management, 23(3), 102-113.

Feys, M., Libbrecht, N., Anseel, F. \& Lievens, F. (2008). A closer look at the relationship between justice perceptions and feedback reactions: the role of the quality of the relationship with the supervisor. Psychologica Belgica, 48(2/3), 27-156.

Franco, L.M., Bennett, S., Kanfer, R., \& Stubblebine, P. (2004). Determinants and Consequences of Health Worker Motivation in Hospitals in Jordan and Georgia. Social Science \& Medicine, 58(2), 343-355.

Gerhart, B., Rynes, S.L., \& Fulmer, I.S. (2009). Pay and performance: individuals, groups, and Executives. The Academy of Management Annals Pay and performance: individuals, groups, and Executives. The Academy of Management Annals, 3(1), 251-315.

Grawitch, M., Gottschalk, M. \& David, M. (2006). The path to a healthy workplace: a critical review linking healthy workplace practices, employee well-being, and organizational improvements. Consulting Psychology Journal: Practice and Research, 58(3), 129-147.

Haines, V. \& Taggar, S. (2006). Antecedents of Team Reward Attitude. Group Dynamics: Theory, Research, and Practice, 10(3), 194205.

Hansen, F., Smith, M., \& Hansen, R.B. (2002). Rewards and Recognition in Employee Motivation. Compensation \& Benefits Review, 34(5), 64-72.

Herzberg, F., Mausner, B., \& Snyderman, B. (1959). The Motivation to Work. New York: Wiley.

Huff, C. (2006). Recognition that resonates. Workforce Management, 85(17), 25-27.

Kim, D. (2006). Employee motivation: Just ask your employees. Seoul Journal of Business Sciences, 12(1), 19-35.

Lawler, E.E. (1992). The Ultimate Advantage: Creating the High Involvement Organization. San Francisco, CA: Jossey-Bass. 
Long, R.J., \& Shields, J.L. (2010). From pay to praise? Non-cash employee recognition in Canadian and Australian firms. The International Journal of Human Resource Management, 21(8), 1145-1172.

Marjolein, F., Anseel, F., \& Wille, B. (2013). Responses to co-workers receiving recognition at work. Journal of Managerial Psychology. 28(5), 492-510.

McAdams, J.L. (1999). Nonmonetary rewards: cash equivalents and tangible awards in Berger, L.A. and Berger, D.R. (Eds), The Compensation Handbook: A State-of-the-Art Guide to Compensation Strategy and Design, McGraw-Hill, New York.

McGregor, D. (1960). The Human Side of Enterprise. New York: McGraw-Hill.

Merriman, K. (2008). Low Trust Teams Prefer Individualized Pay. Harvard Business Review, 86(11), 32.

Porter, L., \& Lawler, E. (1968). Managerial Attitudes and Performance. Homewood: Irwin.

Robbins, S.P. (2005). Motivation:Concepts to Application. Managing and Organizing People. C. University ed. Boston: Pearson.

Robbins, S., Waters-Marsh, T., Cacioppe, R., \& Millet, B. (1994). Organisational Behaviour in Australia and New Zealand. $2^{\text {nd }}$ edition. Sydney: Prentice Hall.

Saunderson, R. (2004). Survey Findings of the Effectiveness of Employee Recognition in the Public Sector. Public Personnel Management, 33(3) 255-276.

Shaw, J.D., Duffy, M.K., \& Stark, E.M. (2000). Interdependence and Preference for Group Work: Main and Congruence Effects on the Satisfaction and Performance of Group Members. Journal of Management, 26(2), 259-279.

Stolovitch, H.D., Clark, R.E., \& Condly, S.J. (2002). Incentives, motivation and workplace performance: research \& best practices. White paper, Incentive Research Foundation.

Thompson, L.L. (2008). Making the team: a guide for managers. New Jersey: Pearson Education, Inc.

Verespej, M. (1999). What each generation wants? Industry Week, 248(19).

Vroom, V.H. (1964). Work and Motivation. New York: Wiley.

World at Work. (2008). Trends in Employee Recognition. Retrieved from http://www.worldatwork.org/waw/adimLink?id=25653\& nonav=yes 